\title{
IMAGENS E O ENSINO DE CIÊNCIAS: A FÍSICA E AS HISTÓRIAS EM QUADRINHOS
}

\author{
Fernando Temporini Frederico, Dulcinéia Ester Pagani Gianotto \\ ${ }^{1}$ Universidade Estadual de Maringá - UEM, Programa de Pós-graduação em Educação para a Ciência e a Matemática, \\ Maringá, PR. Email: ftfrederico2@gmail.com
}

\section{RESUMO}

Este trabalho apresenta algumas das contribuições da utilização das imagens para o ensino de Ciências. Deste modo, será apresentado parte dos resultados de uma pesquisa de doutorado onde se utilizou recursos que fazem uso de imagens para ensinar conceitos de física, dentre eles, as histórias em quadrinhos. Os resultados aqui apresentados, apontaram que tais recursos se mostraram como elementos capazes de contribuir para o ensino de física na medida que ao se aliar conhecimento científico e situações cotidianas, o ensino se torna mais significativo.

Palavras-chave: Imagens; Ensino de Ciências; HQs; Física.

\section{IMAGES AND THE SCIENCE EDUCATION: THE PHYSICAL AND COMICS}

\begin{abstract}
This paper presents some of the contributions the use of images for science teaching. Thus, part of the results will be presented in a doctoral research which we used resources that make use of pictures to teach physics concepts, among them the comics. The results presented here indicated that such resources are shown as elements that contribute to the teaching of physics as that by combining scientific knowledge and everyday situations teaching becomes more significant.
\end{abstract}

Keywords: Images; Science Education; Comics; Physical. 


\section{INTRODUÇÃO}

As tecnologias de comunicação e informação tem ocasionado transformações consideráveis nos mais variados seguimentos da sociedade, principalmente com relação â variedade e velocidade nas quais as informações são apresentadas em nossa sociedade atual.

A internet juntamente com as redes sociais se apresentam como um gigantesco meio de comunicação, nas quais as pessoas que vivem nas mais remotas localidades podem acessar e obter informações de inúmeras fontes, assim como também, podem se comunicar com outras pessoas.

Essa nova dinâmica que tem marcado os últimos anos, tem constantemente, levado a inúmeras discussões sobre as influencias desta nova onda na escola brasileira. Diante desta nova realidade, a escola e consequentemente, o professor se veem obrigados a repensar e a planejar práticas didático pedagógicas que esteja em consonância com essa nova realidade.

Algumas práticas fazem uso de recursos das imagens, tais como fotografias, filmes, softwares, internet, lousas digitais, e também, as HQS - histórias em quadrinhos. Embora as HQs tenham uma longa trajetória ao longo de décadas, sua utilização na escola é historicamente muito recente.

Neste sentido, este trabalho, apresentará os resultados de uma prática pedagógica nas quais as HQs foram utilizadas como forma de contribuir para o ensino de Física.

\section{METODOLOGIA}

A disciplina de Física, assim como a matemática e a química, são disciplinas que devido a exigência de alta abstração, são citadas por muitos estudantes como "difíceis". Muito desta problemática pode estar relacionada, em repetidos casos, com a dificuldade de se estabelecer relações entre o conhecimento físico e nosso cotidiano.

Nesta perspectiva, as $\mathrm{HQs}^{1}$ foram utilizadas como um recurso visando estabelecer, de forma lúdica, relação entre a física e a nossa realidade cotidiana. As mesmas foram exibidas por meio de um datashow com o intuito de "provocar" os estudantes a analisarem o contexto em que a história ocorria, buscando com isso, analisar como os alunos poderiam relacionar o conceito físico com a situação narrada na $\mathrm{HQ}$.

A experiência, aqui relatada, foi realizada no ano de 2014 com alunos do segundo ano do ensino médio, de uma escola pública da rede estadual paranaense do município de Sarandi,

\footnotetext{
${ }^{1}$ Algumas das HQs utilizadas nesta prática foram retiradas do site: http://www.cbpf.br/ caruso/tirinhas e outras, foram confeccionadas por alunos em anos anteriores. 
estado do Paraná, durante a abordagem do conteúdo de ondulatória. Por fazer parte da pesquisa de doutorado, a mesma foi submetida ao Comitê permanente de Ética em Pesquisa com Seres Humanos (COPEP), aprovada sob no 32207914.1.0000.0104.

\section{RESULTADOS}

Uma das HQs utilizadas retratava a natureza de uma onda mecânica. No primeiro quando da história há uma nave espacial, tripulada por um ser extra terrestre que está navegando por alguma parte do universo e, um asteroide se deslocando em direção a mesma.

No quadro seguinte vê-se uma onomatopeia que exprime a colisão da nave com o asteroide e, no último quadro, aparece um outro personagem dizendo "Não é assim! O som não se propaga no espaço vazio."

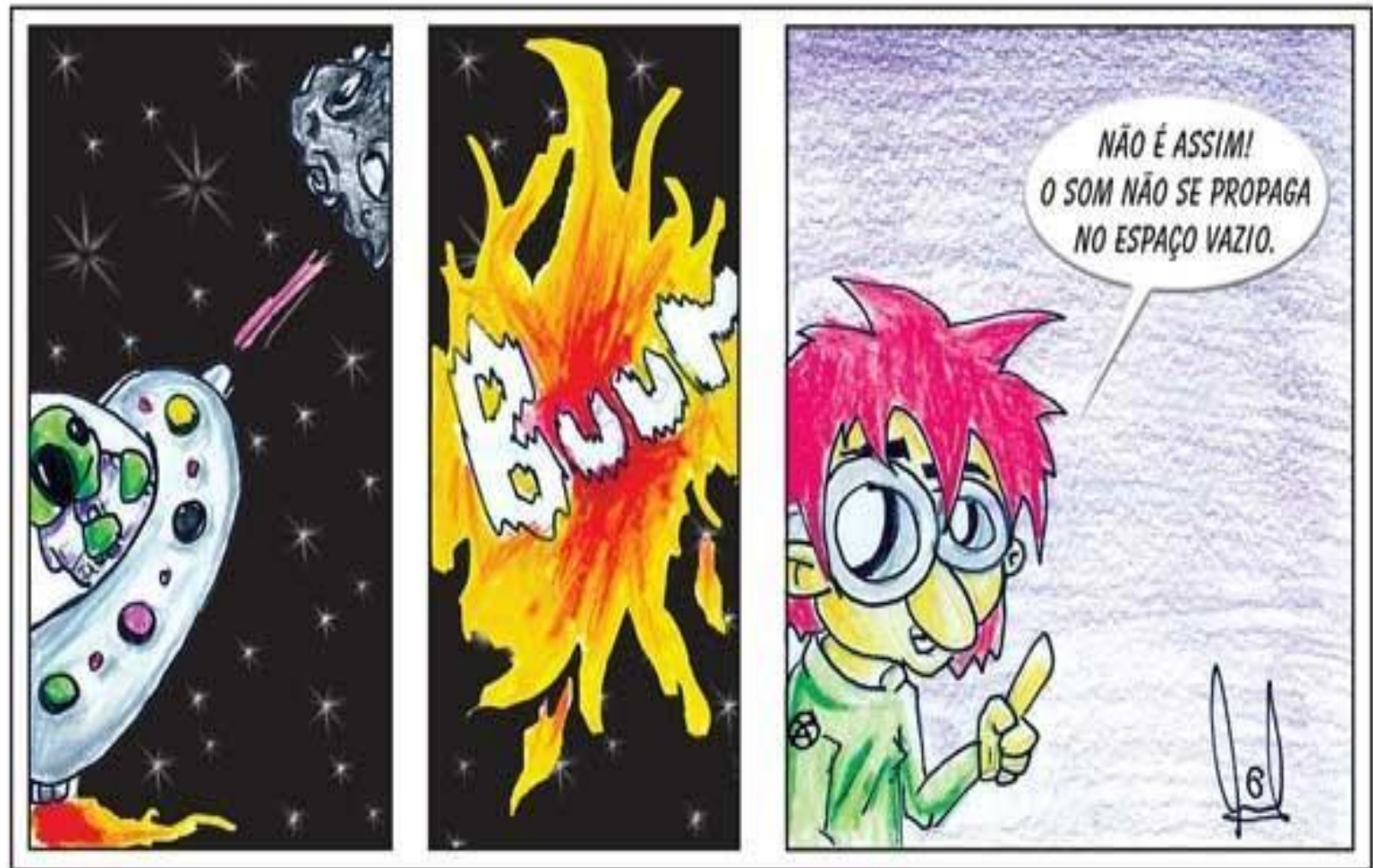

Imagem 1. HQ representando a natureza de uma onda mecânica

Outra HQ utilizada também faz referência a natureza da onda mecânica. Além de conceitos relacionados a elementos físicos da onda mecânica, foi possível também relacionar com aspectos ligados à biologia. 

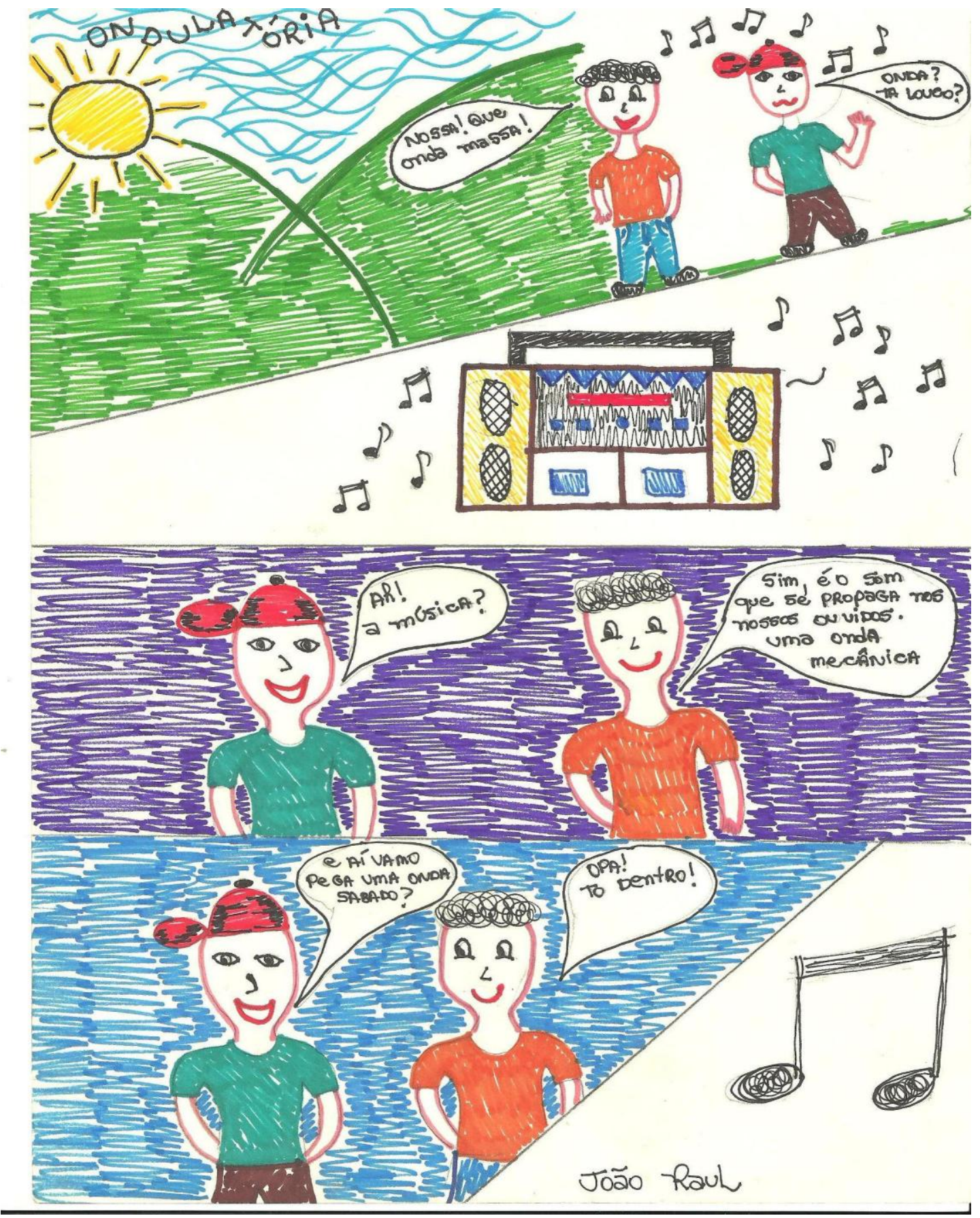

Imagem 2. HQ relacionando onda mecânica com música

Esta segunda $\mathrm{HQ}$ elaborada por um aluno de ensino médio em anos anteriores, busca, de forma divertida e contextualizada, relacionar conceitos de ondulatória com música. No primeiro quadro, se passa o diálogo entre dois personagens em que um deles ao ouvir o som de uma música, indaga "Nossa que onda massa" - exprimindo que a música é legal, boa. Já o outro personagem fica sem entender o porquê do termo onda, uma vez que não consegue estabelecer relação entre onda mecânica e a música. 
Nos quadros seguintes um dos personagens se encarrega de explicar ao colega a relação entre o termo onda e a música, encerrando o diálogo após planejar pegar uma onda no final de semana, ou seja, de ir a um local em que haja música.

Tanto a primeira, quanto a segunda $\mathrm{HQ}$ abordam a natureza de uma onda mecânica, ou seja, aquela que necessita de um meio material para se propagar. Embora a narrativa da primeira $\mathrm{HQ}$ se passe no espaço, local desconhecido para a maioria de nós, a mesma oferece vários elementos nas quais se podem discutir termos bem utilizados na física. Por exemplo, o som não se propaga no vácuo (local com ausência de matéria) e, a onomatopeia BUUM sugere o contrário, deste modo, foi possível discutir com os alunos o porquê da "explicação" do personagem no terceiro quadro, enfatizando que o som não se propaga no espaço vazio.

Neste momento várias outras questões foram exploradas, tais como que tipo de onda é capaz de se propagar no vácuo, como é o caso das ondas eletromagnéticas, quais as relações de frequência e energia, suas aplicações e, até mesmo, como a ciência (física e astronomia em particular), tem buscado evidencias de vida em outros planetas.

Já com a segunda $H Q$, além das relações de onda mecânica e som, foram também exploradas questões relacionadas com a voz e a audição, estabelecendo neste caso, uma relação interdisciplinar entre física e biologia. Além disso, também foram abordados os problemas que a exposição a sons de alta intensidade, principalmente com relação ao uso frequente dos fones de ouvidos, podem afetar a qualidade de nossa audição.

\section{DISCUSSÕES}

Na educação, não são poucos os casos de experiências educacionais onde são utilizadas imagens pelos professores, como recursos didáticos, tais como: vídeos, fotografias, histórias em quadrinhos, softwares, dentre outros.

Vê-se, portanto, que uma imagem é capaz de carregar muito mais significado do que imaginamos, sendo usada para muitos fins, inclusive na educação. Em alguns casos, os traços, cores, formas, sombras, movimentos de uma imagem, dentre outros elementos são capazes de contribuir para processos que envolvem o ensino e a aprendizagem, como na utilização de softwares para ensinar conceitos de astronomia (Frederico, 2013) e uso de histórias em quadrinhos como recurso metodológico no ensino de física (Frederico e Gianotto, 2012).

As imagens, portanto, podem ser utilizadas para muitas funções, inclusive neste nosso caso de estudo, que envolve processos de ensino e aprendizagem relacionados com conceitos e conteúdos de física. 
A utilização de recursos como as HQs é uma forma de dinamizar, em muitos casos, a abordagem de conteúdos e conceitos, como citado neste trabalho. As HQs e as imagens, cores e tracejados nelas dispostas são recursos que trabalham tanto com a linguagem verbal e não verbal.

Nesta perspectiva, Aumont (1995) argumenta que a produção de uma imagem não é realizada de forma gratuita, pois, as mesmas sempre foram produzidas para determinados fins, sejam eles coletivos ou individuais. E, uma das razões fundamentais da produção das imagens provém justamente da vinculação das imagens em geral com o "domínio do simbólico", ou seja, aquilo que possibilita que elas ocupem a posição de mediação entre o espectador e a realidade (AUMONT, 1995, p.78).

Já Joly (1996, p. 14) afirma que “[...] a imagem seria um objeto segundo com relação a um outro que ela representaria de acordo com certas leis particulares." Por outro lado, Neiva Junior $(1986$, p. 5) salienta que "a imagem é basicamente uma síntese que oferece traços, cores e outros elementos visuais em simultaneidade." Pode-se observar que independente das propostas de definições citadas, as imagens são elementos capazes de representar algo, sendo indiscutível este seu poder de representação.

Referindo-se a relação da imagem com o real, Aumont (1995) faz referência à tricotomia sugestiva e cômoda entre valores das imagens e suas relações com o real proposta por Rudolf Arnhein (1969): um valor de representação; um valor de símbolo e um valor de signo.

O valor de representação refere-se justamente aquelas imagens representativas, ou seja, as que representam coisas concretas, um exemplo, seria uma fotografia de uma pessoa. Já o valor de símbolo, está relacionado com a imagem simbólica, que representa coisas abstratas. Um exemplo seria a imagem de um coração, que poderia representar o "sentimento de amor". Enquanto que o valor de signo se estende aquelas imagens capazes de representar informações cujos elementos não são visualmente refletidos por ela. Como exemplo, poderíamos citar o sinal de trânsito, que a cor indicada pelo aparelho indica se o condutor pode ou não avançar.

Rama et al (2004, p. 22) afirmam que palavras e imagens, juntos, "ensinam de forma mais eficiente", uma vez que a interligação do texto com a imagem, como é comum no caso das HQs, podem contribuir para a compreensão de conceitos de uma forma que, tais códigos dispostos isoladamente, não teriam a mesma eficácia.

Nas HQs o texto e a gravura se completam e as noções que as palavras sugerem passam a ser mais concretas através das ilustrações e ainda, as mesmas oferecem ilustrações que apresentam e representam as coisas e objetos concretamente, oferecendo condições para progressiva abstração (ANSELMO, 1975). 
Além destas questões, Cirne (1973) destaca que os quadrinhos é um instrumento de muita relevância para fins educacionais, inclusive sobre a formação moral e de significação cultural. Como foi possível verificar, a utilização das HQs como na experiência citada, funciona como um elemento capaz de relacionar de forma lúdica conhecimento científico e o cotidiano.

Calanzas (2008) por sua vez esclarece que os quadrinhos por pertencerem à categoria de mídia impressa, são similares aos livros, deste modo, o contato com esta mídia pode gradualmente contribuir para o hábito da leitura de outras mídias, tais como livros e revistas.

É claro que o professor deve estar atento para correção de possíveis distorções que podem ser geradas em torno de metáforas que podem ser apresentadas nas HQS. Por isso, é necessário o conhecimento sobre a temática abordada, pois, não se deve correr o risco de ficar na superficialidade dos conceitos, principalmente se tratando de alunos do ensino médio.

\section{CONSIDERAÇÕES FINAIS}

Considerando os resultados alcançados, verifica-se que as HQs se mostraram como um recurso capaz de contribuir para processos que envolvem ensino e aprendizagem, como neste caso, do ensino de física.

Seu potencial pode ser verificado principalmente em levantar conhecimentos prévios sobre a temática abordada, assim como também, na capacidade de relacionar conhecimentos científicos com rotinas do cotidiano.

Além disso, as imagens, em diversas ocasiões, carregam consigo a capacidade de expressar informações de uma maneira que as palavras não conseguiriam exprimir. Nas HQs, as imagens ocupam um lugar de destaque, uma vez que é por meio das mesmas que se pode representar ludicamente conceitos que se pretende evidenciar.

Neste sentido, sugere-se que os professores das mais variadas áreas do conhecimento façam uso das imagens, assim como nas HQs, na medida em que elas se apresentam como recursos capazes de contribuir consideravelmente para o ensino, como no caso da experiência aqui apresentada.

\section{REFERÊNCIAS}

AUMONT, Jacques. A imagem. 2. ed. Campinas: Papirus, 1995.

ANSELMO, Zilda Augusta. Histórias em quadrinhos. Petrópolis: Cortez, 1975.

CALANZAS, Flávio. História em quadrinhos na escola. São Paulo: Paulus, 2008. 
CIRNE, Moacir. Para ler quadrinhos: da narrativa cinematográfica à narrativa quadrinizada. Petrópolis: Vozes, 1972.

FREDERICO, Fernando Temporini. Contribuições de recursos da informática nos processos de ensino e aprendizagem: utilização de softwares livres para potencializar e dinamizar o Ensino de Ciências. 143 fls. Dissertação (Mestrado em Educação para a Ciência e a Matemática) Universidade Estadual de Maringá, Maringá, 2013.

FREDERICO, Fernando Temporini; GIANOTTO, Dulcinéia Ester Pagani. Metodologia do Ensino de Ciências: contribuição da utilização de histórias em quadrinhos para ensinar física. Nupem, v. 4, p. 199-215, 2012.

JOLY, Martine. Introdução a Análise de imagens. Campinas: Papirus, 1996.

NEIVA JUNIOR, Eduardo. A imagem. São Paulo: Ática, 1986

RAMA, Angela et al. Como usar histórias em quadrinhos na sala de aula. São Paulo: Contexto, 2004. 